\title{
The relationship between particulate matter and childhood respiratory complaints and peak expiratory flows in Harran agricultural area
}

\author{
Zafer Hasan Ali Sak ${ }^{1 \oplus}$, Şerif Kurtuluş ${ }^{1 \oplus}$, Birsen Ocaklı² ${ }^{2 \oplus}$, Zehra Nur Töreyin ${ }^{3 \oplus}$, \\ İbrahim Bayhan ${ }^{4 \oplus}$, M. İrfan Yeşilnacar ${ }^{4 \oplus}$, Metin Akgün ${ }^{5 \oplus}$, İlknur Arslanoğlu ${ }^{6 \oplus}$, \\ Peri Meram Arbak ${ }^{70}$ \\ ${ }^{1}$ Department of Chest Diseases, Harran University Faculty of Medicine, Şanliurfa; ${ }^{2}$ Chest Diseases and Thoracic Surgery Süreyyapaşa \\ Training and Research Hospital, Istanbul; ${ }^{3}$ Department of Occupational Health and Occupational Diseases, Ege University Faculty \\ of Medicine, İzmir; ${ }^{4}$ Department of Environmental Engineering, Harran University Engineering Faculty, Şanliurfa; ${ }^{5}$ Department of \\ Chest Diseases, Atatürk University Faculty of Medicine, Ankara; Departments of ${ }^{6}$ Pediatric Endocrinology and ${ }^{7}$ Chest Diseases, Düzce \\ University Faculty of Medicine, Düzce, Turkey.
}

\begin{abstract}
Background. In recent years, many studies have evaluated the increasing incidence of asthma and chronic respiratory diseases among children living close to rural areas with pesticide application. Pesticide exposure in 266 children (126 girls and 140 boys) in Şanlıurfa, a cotton-producing province in Turkey, was explored in this work. Four different villages spread over $40 \mathrm{~km}^{2}$ were included.

Methods. Measurements of peak expiratory flow (PEF) in 266 children were conducted in late June, before intensive pesticide applications in the cotton-producing fields. The measurements were repeated for 72 of 266 children after pesticide application in late August. PEF, particulate matter with diameter less than $2.5 \mu \mathrm{m}$ $\left(\mathrm{PM}_{2.5}\right)$, particulate matter with diameter less than $10 \mu \mathrm{m}\left(\mathrm{PM}_{10}\right)$, temperature, humidity, and wind speed were measured.

Results. After pesticide application, mean $\mathrm{PM}_{2.5}$ and $\mathrm{PM}_{10}$ values were significantly increased compared to before pesticide application ( $p<0.001$ for both parameters). After pesticide exposure, nasal discharge, sneezing, burning and itching in the eyes, cough, sputum production, wheezing, shortness of breath and chest tightness were significantly increased $(p<0.001)$. The mean PEF value was demonstrated to decrease significantly after pesticide application $(p<0.001)$. Moreover, significant negative correlations were noted between PEF and PM 10 and between PEF and $\mathrm{PM}_{2.5}(p<0.001)$.

Conclusions. Intensive pesticide application causes respiratory dysfunction and increased respiratory complaints in children living near the affected agricultural areas, and impacts quality of life adversely. The results of this work can be used to develop an early warning system and methods to prevent respiratory disorders in children residing in the study area.
\end{abstract}

Key words: pesticide exposure in children, Peak expiratory flow, $\mathrm{PM}_{10}, \mathrm{PM}_{2.5}$.

Pesticides have been used in agricultural applications to destroy pests and weeds. They include insecticides, herbicides, fungicides and rodenticides. Children are exposed to pesticides

$\bowtie$ Zafer Hasan Ali Sak drsak19@gmail.com

Received 21st January 2020, revised 21st May 2020, 13th July 2020, accepted 22nd July 2020. via air, food, dust, soil and touching surfaces contaminated with pesticides. In areas with widespread agricultural production, pesticides in powder form are known to affect children via inhalation, and the dimensions of pesticide particulate matter (PM) play a role in its movement and deposition. Regional transport over several kilometres may be responsible for unwanted effects on non-target species. ${ }^{1}$ 
The amount of pesticide in dust collected from households near agricultural areas was found to be high, and increased concentrations of pesticide metabolites have been reported in the urine of children residing near such areas., ${ }^{2,3}$ The health effects of pesticide exposure on children include nausea, vomiting, seizures, bloody urination and skin lesions, and different systems of the body, including the respiratory system, are affected. Clinical manifestations such as aspiration pneumonia and asthma have also been observed. ${ }^{1}$ Organophosphate pesticides result in decreased forced vital capacity (FVC) and forced expiratory volume in one second $\left(\mathrm{FEV}_{1}\right)$ in children. ${ }^{4}$

$\mathrm{PM}$ is a contaminant group consisting of a mixture of organic and inorganic substances in solid or liquid form in air. It can reach harmful concentrations in indoor and outdoor environments during pesticide application. The aerodynamic diameters of $\mathrm{PM}_{10}$ and $\mathrm{PM}_{2.5}$ are smaller than $10 \mu \mathrm{m}$ and $2.5 \mu \mathrm{m}$, respectively. ${ }^{5}$ While emissions of motor vehicles are the main source of $\mathrm{PM}_{2.5}, \mathrm{PM}_{10}$ consists of a mixture of carbon and organic compounds, acids and fine metal particles. Pesticides can be found in both $\mathrm{PM}_{10}$ and $\mathrm{PM}_{2.5^{\prime}}$ or cling to the surfaces of these particles. ${ }^{6,7}$

Saharan dust outbreaks in the Eastern Mediterranean region occur predominantly during winter owing to the cold-core midlatitude Mediterranean cyclones, and during spring due to the Sharan cyclones. 8 .9 The frequency of synoptic-scale meteorological events and, accordingly, dust transport cases increase significantly in spring and autumn. Both the number of patients with respiratory complaints and $\mathrm{PM}_{10}$ levels in air reach their peaks in late January and early February, respectively. Contrary to expectations, the number of patients decrease significantly during June, when only dry dust events prevail. Processes that help to wet the organic fraction of the desert dust curtain play an important role in health. ${ }^{9}$
As children breathe at a faster rate than adults, they inhale more air in relation to their body weight. ${ }^{10}$ The respiratory tract in a child is shorter, smaller and more permeable to air pollutants, and therefore, such pollutants, including PM, easily enter children's lungs and cause irritation, inflammation and acute or chronic respiratory problems. ${ }^{11}$ Children living in urban areas are exposed to air pollution because of heavy exhaust fumes. Children residing in rural neighbourhoods are exposed to PM generated by biomass burning in their homes and the application of pesticides in agricultural areas. Children of immigrant and asylum-seeking families are exposed to smoke from stoves used in tents. ${ }^{12}$ A follow-up study of a Swedish cohort of children from 1992 2001 showed a decrease in the frequency of chronic cough, bronchitis, colds, dry cough and conjunctivitis with a reduction in $\mathrm{PM}_{10}$ levels. ${ }^{13}$

After increased admissions of children living in agricultural areas with respiratory complaints to our hospital during the pesticide application season, we decided to investigate whether the complaints were related to the pesticide application in these regions. Thus, the purpose of this study was to measure the peak expiratory flow (PEF) rates before and after pesticide application, record upper and lower respiratory tract complaints among children residing in those areas, and explore the relationship of these data with $\mathrm{PM}_{10}$ and $\mathrm{PM}_{2.5}$ levels.

\section{Materials and Methods}

\section{Study population}

Following the approval of the Ethics Committee of Harran University, Turkey (May 6, 2016/18), we designed a population-based prospective cohort study to investigate the role of environmental risk factors in increased respiratory symptoms in children living in agricultural areas during pesticide application. A total of 266 volunteers (126 girls and 140 boys) from Şanlıurfa, a cotton-producing 
province in Turkey, were recruited from 4 different villages spread over $40 \mathrm{~km}^{2}$. The mean age of the 266 children who participated in the study before pesticide application was $10.7 \pm 2.6$ years (minimum: 6 years, maximum: 16 years), while the median age was 11 years. The mean age of the 266 children who participated in the study after pesticide application was 10.5 \pm 2.4 years (minimum: 6 years, maximum: 16 years), while the median age was 10.5 years. Moreover, 133 of the children (ages 6-10 years) were primary school students, while the remaining 133 children (ages 10-15 years) attended middle school. Eight (3\%) of the 266 children who participated in the study before pesticide application had a diagnosis of asthma. Measurements for the respiratory function of the 266 children were performed in late June, before intensive pesticide application to the cottonproducing fields. The parents of the children who participated in the study provided their informed consent. This study was conducted in accordance with the Declaration of Helsinki and Good Clinical Practice guidelines.

\section{Application area}

The study was conducted in Harran city of Şanlıurfa province, southeast Turkey, between June and August 2016. Cotton farming is one of the main sources of livelihood in Şanlıurfa province. As mentioned previously, the research was conducted with children living in the following 4 villages scattered over an area of $40 \mathrm{~km}^{2}$ : Giyimli (N36.56 E39.00), Küçük Minareli (N36.55 E39.00), Büyük Minareli (N36.56, E38.09) and Bozyaz1 (N36.51, E39.05). The children were evaluated before the application of the pesticides (Fig.1). Pesticide application was conducted over a time interval of 10-12 d. The application started in the third week of June and continued until the end of August. Tractors with agricultural sprayer machines were used for pesticide spraying.

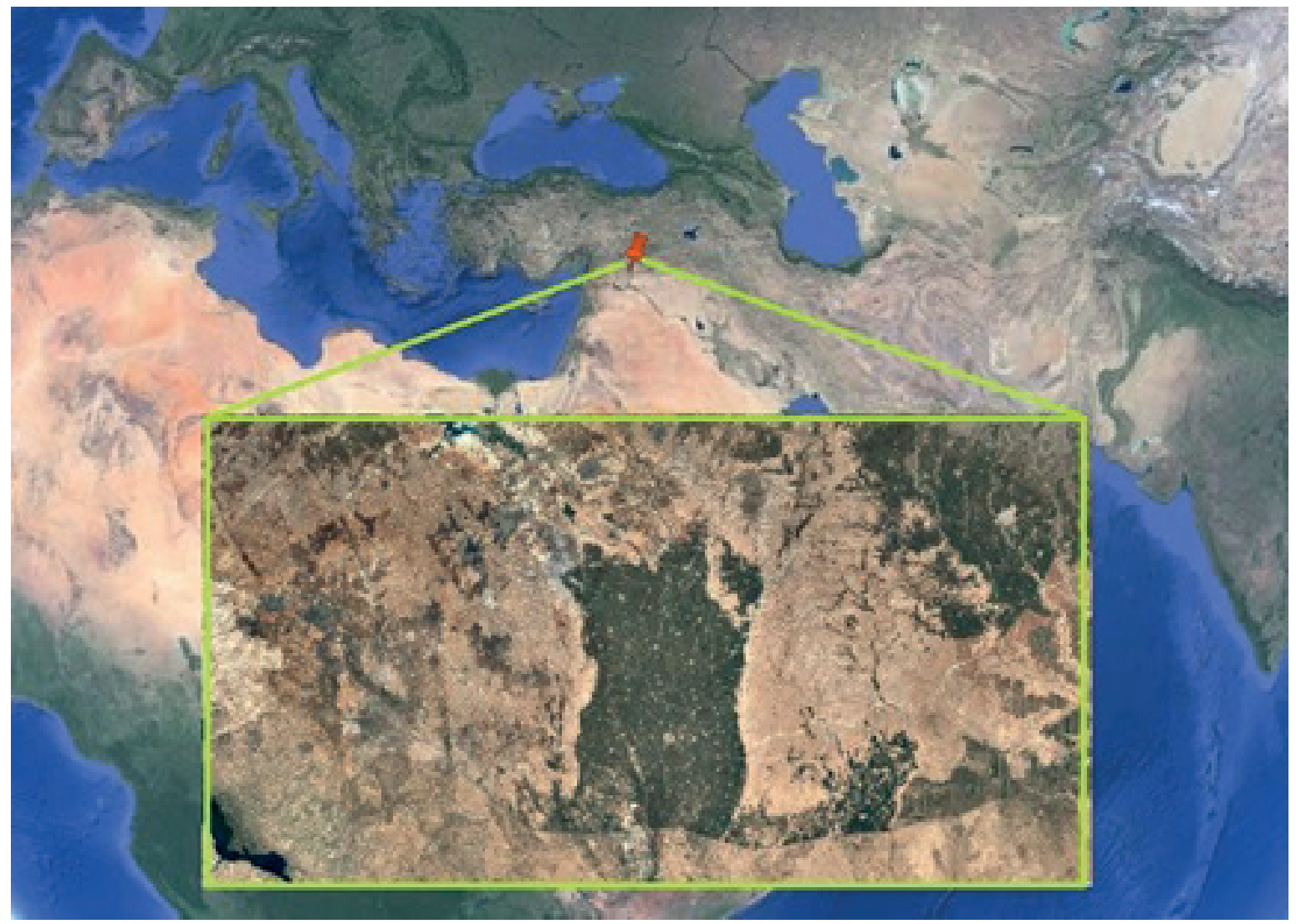

Fig. 1. Study location (the red maker indicates intensive pesticide application area). 


\section{Applied pesticides}

The pesticide was a mixture of lambdacyhalothrin (7 g/daa; grams per decare), emamectin benzoate (4 g/daa), nitrogen (40 g/ daa), phosphorus pentoxide (200 g/daa) and zinc (120 g/daa). It was applied to kill green worms (Helicoverpa armigera), which are harmful to cotton plants.

Measurement of particulate matter $\left(\mathrm{PM}_{2.5}\right.$ and $\mathrm{PM}_{10}$ ) Two pDR-1500 cyclones (Personal DataRAM Pdr, Thermo Scientific, USA) were used to measure $\mathrm{PM}_{10}$ and $\mathrm{PM}_{2.5}$ concentrations (in $\mu \mathrm{g} / \mathrm{m}^{3}$ ). The necessary calibration apparatus was used for instrument calibration before each sampling. Post-pesticide PEF measurements were conducted on the second day of pesticide application. Before starting the sampling, the coordinates and altitude of the working area were determined with a GPS device (Magellan, USA). Fifteen-minute measurements of $\mathrm{PM}_{10}$ and $\mathrm{PM}_{2.5}$ were made with the cyclones in the four villages before pesticide application (in June) and after it (in August). Weather parameters (temperature, humidity and wind speed) were also recorded on the sampling dates.

Children and/or their parents were asked to report any issues pertaining to the nose, throat and eyes, as well as cough, sputum production, wheezing, dyspnea and chest tightness before and after pesticide application. PEF is the maximum expiration rate recorded during a forced expiration. PEF measurements are frequently used in the follow-up of asthma and epidemiological studies. They also serve as a suitable method of respiratory function assessment in children. However, PEF measurements are affected by anthropometric parameters such as age, height, weight, gender, air quality, climate (temperature and humidity), atmospheric air pressure (wind and altitude) and nutritional status. ${ }^{14-16}$ PEF rates were measured in the children before and after pesticide application with a Mini-Wright Peak Flow Meter (Clement Clarke International, UK) in a closed environment (village rooms, schools and reeve rooms). Post-pesticide PEF measurements were conducted on the second day of pesticide application. All the measurements were taken by the same four people ( $\mathrm{ZS}, \mathrm{SH}, \mathrm{PA}$ and $\mathrm{BO}$ ). The measurements were conducted with the subject in standing position. At least three technically acceptable PEF measurements were collected, and the highest absolute PEF value was recorded.

\section{Statistical analysis}

The data collected were analysed with the Statistical Package for Social Sciences (SPSS) software (version 21.0, SPSS Inc., US). An independent samples $t$-test was used to compare independent groups, while paired samples $t$-test was applied to compare the dependent groups. The distribution of categorical variables in both groups was compared with Pearson's chi-square test. The data were expressed as mean \pm standard deviation (SD). Categorical variables were expressed as frequencies and percentages. Pearson's correlation analysis was used to detect the relationships between age, $\mathrm{PM}_{10}$ and $\mathrm{PM}_{2.5^{\prime}}$ wind speed, humidity, heat and PEF rates. A linear regression analysis was used to detect the independent effects of $\mathrm{PM}_{10}$ and $\mathrm{PM}_{2.5}$, wind speed, humidity and heat on the PEF rates. Statistical significance was assumed for $p<0.05$.

\section{Results}

The children were evaluated for respiratory functions and symptoms related to agricultural pesticide exposure before and after pesticide application in the study area. Of the study subjects in the four villages, 140 (52.6\%) were male and $126(47.4 \%)$ were female. Moreover, $104(39.1 \%), 102(38.3 \%), 37$ (13.9\%) and 23 (8.6\%) came from Giyimli, Küçük Minareli, Büyük Minareli and Bozyazı, respectively. After pesticide application, 72 children from the initial group were re-evaluated in late August. Of these 72 children, 33 (45.8\%), 15 (20.8\%), $17(23.6 \%)$ and 7 (9.7\%) were from Giyimli, Küçük Minareli, Büyük Minareli and Bozyazı, respectively. 
The measurements of $\mathrm{PM}_{2.5^{\prime}} \mathrm{PM}_{10^{\prime}}$ wind speed, temperature and humidity before and after pesticide application are shown in Table I. Before pesticide application, the mean $\mathrm{PM}_{2.5}$ and $\mathrm{PM}_{10}$ values were 4.7 and 11.7 for Giyimli, 5.19 and 27.8 for Küçük Minareli, 14.5 and 27.8 for Büyük Minareli, and 12.2 and $23.8 \mu \mathrm{g} / \mathrm{m}^{3}$ for Bozyazı. After pesticide application, the corresponding values changed to 13.2 and 334 for Giyimli, 11.2 and 328 for Küçük Minareli, 15 and 313.5 for Büyük Minareli and 13.21 and $319 \mu \mathrm{g} / \mathrm{m}^{3}$ for Bozyazı. The regions with pesticide-sprayed fields showed significantly increased values of $\mathrm{PM}_{2.5}$ and $\mathrm{PM}_{10}$ compared to those before the pesticide application. The air temperature during the study period (June to August) showed an increase, in line with normal seasonal variation. Humidity levels doubled as a result of the irrigation of fields surrounding the study area. Wind speed was found to have decreased during pesticide spraying in the study period.

Examination of the respiratory functions of the participating children, as well as their eye, nose, throat and respiratory complaints before and after the pesticide application are shown in Table II. All of these complaints increased significantly after pesticide application due to the unpleasant smell resulting from the applied pesticide. Table III shows the incidences of eye, nose, throat and respiratory complaints of 72 children who were tested before and after the pesticide application. It was observed that all respiratory complaints of the 72 children increased significantly after the pesticide application. Unfortunately, the children could not be evaluated in groups due to decreased participation after pesticide application. The mean PEF of the 256 children before the application of pesticide was $261.0 \pm$ $75.7 \mathrm{~mL} / \mathrm{s}$ (minimum: $120 \mathrm{~mL} / \mathrm{s}$, maximum: 530 $\mathrm{mL} / \mathrm{s}$ ), while the corresponding value after the application was $231.1 \pm 65.7 \mathrm{~mL} / \mathrm{s}$ (minimum: $60 \mathrm{~mL} / \mathrm{s}$, maximum: $450 \mathrm{~mL} / \mathrm{s})(p<0.001)$. The PEF values were measured in 72 children after pesticide application. The mean PEFs of the same 72 children before and after pesticide application were $263.1 \pm 67.0 \mathrm{~mL} / \mathrm{s}$ (minimum: $120 \mathrm{~mL} / \mathrm{s}$, maximum: $480 \mathrm{~mL} / \mathrm{s}$ ) and $231.1 \pm$

Table I. Environmental measurements before and after pesticide application.

\begin{tabular}{lccc}
\hline & \multicolumn{2}{c}{ Pesticide application } & p \\
\cline { 2 - 3 } & Before & After & $<0.0001$ \\
\hline PM2.5 $\left(\mu \mathrm{gr} / \mathrm{m}^{3}\right)$ & $6.9 \pm 3.6$ & $12.7 \pm 1.2$ & $<0.0001$ \\
PM10 $\left(\mu \mathrm{gr} / \mathrm{m}^{3}\right)$ & $18.2 \pm 5.8$ & $327.9 \pm 7.3$ & $<0.0001$ \\
Temperature $\left({ }^{\circ} \mathrm{C}\right)$ & $32.5 \pm 1.2$ & $37.9 \pm 0.5$ & $<0.0001$ \\
Humidity $(\%)$ & $26.6 \pm 2.6$ & $53.1 \pm 0.9$ & $<0.0001$ \\
Wind speed $(\mathrm{m} / \mathrm{s})$ & $27.3 \pm 4.8$ & $21.0 \pm 0.0$ & \\
\hline
\end{tabular}

*the values show mean \pm SD

Table II. Frequency of respiratory symptoms before and after pesticide application.

\begin{tabular}{|c|c|c|c|c|c|}
\hline \multirow{3}{*}{ Symptoms } & \multicolumn{4}{|c|}{ Pesticide application } & \multirow{3}{*}{$\mathrm{p}$} \\
\hline & \multicolumn{2}{|c|}{ Before $(n=266)$} & \multicolumn{2}{|c|}{ After $(\mathrm{n}=72)$} & \\
\hline & $\mathrm{n}$ & $\%$ & $\mathrm{n}$ & $\%$ & \\
\hline Mouth-nose-throat burning & 29 & 10.9 & 45 & 62.5 & $<0.0001$ \\
\hline Eye burning & 31 & 11.7 & 47 & 65.3 & $<0.0001$ \\
\hline Cough & 34 & 12.8 & 46 & 63.9 & $<0.0001$ \\
\hline Sputum & 14 & 5.3 & 38 & 52.8 & $<0.0001$ \\
\hline Wheezing & 10 & 3.8 & 43 & 59.7 & $<0.0001$ \\
\hline Dyspnea & 15 & 5.6 & 47 & 65.3 & $<0.0001$ \\
\hline Chest tightness & 19 & 7.1 & 43 & 59.7 & $<0.0001$ \\
\hline
\end{tabular}


Table III. Evaluation of respiratory symptoms within same individuals before and after pesticide application.

\begin{tabular}{|c|c|c|c|c|c|}
\hline \multirow{3}{*}{ Symptoms } & \multicolumn{4}{|c|}{ Pesticide application } & \multirow{3}{*}{$\mathrm{p}$} \\
\hline & \multicolumn{2}{|c|}{ Before $(n=72)$} & \multicolumn{2}{|c|}{ After $(n=72)$} & \\
\hline & $\mathrm{n}$ & $\%$ & $\mathrm{n}$ & $\%$ & \\
\hline Mouth-nose-throat burning & 9 & 12.5 & 45 & 62.5 & $<0.0001$ \\
\hline Eye burning & 9 & 12.5 & 47 & 62.5 & $<0.0001$ \\
\hline Cough & 10 & 13.9 & 46 & 65.3 & $<0.0001$ \\
\hline Sputum & 3 & 4.2 & 38 & 52.8 & $<0.0001$ \\
\hline Wheezing & 3 & 4.2 & 43 & 59.7 & $<0.0001$ \\
\hline Dyspnea & 4 & 5.6 & 47 & 65.3 & $<0.0001$ \\
\hline Chest tightness & 10 & 13.9 & 43 & 59.7 & $<0.0001$ \\
\hline
\end{tabular}

Table IV. Relationship between PEF and environmental factors before pesticide application.

\begin{tabular}{lccccc}
\hline & PM2.5 & PM10 & Heat & Wind speed & Humidity \\
\hline PEF & & & & & \\
$\mathrm{r}$ & 0.094 & 0.071 & 0.019 & 0.137 & -0.026 \\
$\mathrm{p}$ & 0.137 & 0.266 & 0.766 & 0.030 & 0.681 \\
\hline
\end{tabular}

Table V. Correlations between PEF values and environmental factors after pesticide application.

\begin{tabular}{lcccc}
\hline & PM2.5 & PM10 & Heat & Humidity \\
\hline PEF & & & & \\
$\mathrm{r}$ & 0.217 & -0.295 & 0.135 & -0.135 \\
$\mathrm{p}$ & 0.067 & 0.012 & 0.259 & 0.259 \\
\hline
\end{tabular}

$65.7 \mathrm{~mL} / \mathrm{s}$ (minimum: $60 \mathrm{~mL} / \mathrm{s}$, maximum: 450 $\mathrm{mL} / \mathrm{s})$, respectively $(p<0.0001)$. No statistically significant differences were observed between the 194 children who participated in the first PEF measurement and the 72 children who participated in the second half of the study in terms of average age $(10.8 \pm 2.7$ to 10.5 \pm 2.4 years; $p=0.457$ ) and gender distribution (while the rate of girls participating in the study before pesticide application was 50.5\%, after application it dropped to $39 \%$, and the corresponding rates for the boys were 49.5 to $61.5 \% ; p=0.060$ ). These results were excluded from the discussion that follows, as these exerted no effects on the results of this study.

A significant positive correlation was observed between the PEF values measured before $(r=$ $0.680, p<0.001)$ and after $(r=0.438, p<0.001)$ pesticide application. There was no significant difference between the mean PEF values of girls $(255.8 \pm 71.4 \mathrm{~mL} / \mathrm{s})$ and boys $(265.4 \pm 79.3$
$\mathrm{mL} / \mathrm{s})$ before pesticide application $(p=0.318)$. The mean PEF value of girls after pesticide application $(202.8 \pm 63.3 \mathrm{~mL} / \mathrm{s})$ was significantly lower than that of the boys $(249.1 \pm 61.3 \mathrm{~mL} / \mathrm{s})(p$ $=0.03$ ). PEF values can be affected by $\mathrm{PM}_{2.5}$ and $\mathrm{PM}_{10}$ concentrations, wind speed, temperature and humidity in the pesticide application area. For this reason, the PEF values were assessed with environmental factors to determine the correlation among them. Before pesticide application, PEF and wind speed alone were positively related (Table IV). After pesticide application PEF was found to be significantly negatively correlated with $\mathrm{PM}_{10}$ (Table $\mathrm{V}$ and Fig. 2). The linear regression analysis showed that $\mathrm{PM}_{10}$ measured after pesticide application was independent of PEF $(B=-2.706, t=-2.425$, and $p=0.018)$. While no significant differences were observed for PEF $(p=0.059)$ and wind speed $(p=1.000)$ among four villages after pesticide application, significant differences 


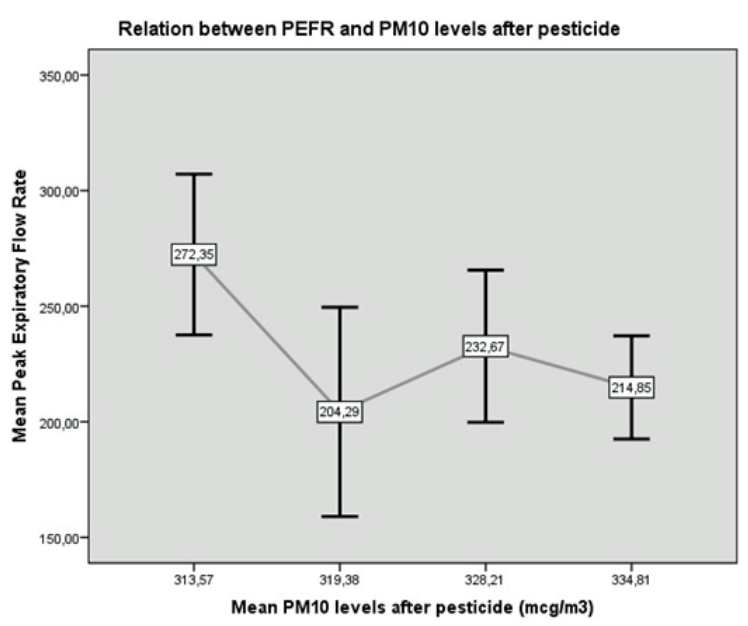

Fig. 2. Negative relationship between PEF and PM10 levels after pesticide application.

existed for temperature $(p<0.001)$, humidity $(p<0.001), \operatorname{PM}_{10}(p<0.001)$ and PM $(p<0.001)$ according to the results of the Kruskal-Wallis test.

\section{Discussion}

It is natural to believe that rural farmers are blessed with clean air and a naturally healthy environment. However, farming is rife with the hazards posed by pesticide application and many other respiratory hazards. Approximately five billion pounds of pesticides are consumed worldwide annually. ${ }^{17}$ Among these pesticides, organophosphate and carbamate insecticides are the most commonly used. ${ }^{18}$ Toxic pesticides are widely applied to control pests and pest-related diseases in agriculture, fishery, forestry and the food industry, leading to their dissemination to the environment. ${ }^{16}$ Although non-toxic or less toxic and harmless strategic alternatives exist, they are often overlooked. The toxic effects of pesticides are particularly intense among children, elderly and women living in agricultural areas due to their heightened exposures. ${ }^{18-23}$ Awareness about the risks of pesticide exposure to human life, and especially later ages in the case of children, is lacking. Pesticide exposure can cause asthma, allergic rhino-sinusitis and chronic bronchitis in the respiratory tract. ${ }^{24-30}$ Our study investigated the acute effects of exposure to pesticide, because the long-term effects of pesticides on humans are yet to attract sufficient attention. In addition to pesticide-related complaints in children, PEF measurements were performed in order to make it easier for the children to adapt to the pulmonary function tests. The PEF values before and after pesticide application varied due to the irritation caused by the pesticide exposure, particularly in the respiratory tract. The most well-known outdoor allergens in Şanlıurfa are meadow and grain pollen. Meadow pollen levels are at their highest level in May. ${ }^{31}$ Although the time period for the pollination of grain pollen varies regionally, it typically begins in March and continues until the end of May. ${ }^{32}$

Our study revealed that children living near areas with agricultural pesticide application suffered from a significant increase in upper and lower respiratory tract complaints and a significant decrease in PEF values after pesticide application. The decrease in PEF was significantly negatively correlated with the increase in $\mathrm{PM}_{10}$ values. In children exposed to PM originating from a mixture of lambdacyhalothrin (7 g/daa) and emamectin benzoate (4 g/daa), the upper and lower respiratory tract complaints increased in the short term, while the respiratory function decreased. Our study observed that the average PEF values of girls decreased to a greater extent than those of boys after pesticide application. A review investigating whether boys or girls are more affected by air pollution, be it outdoors or indoors, showed that children's hormonal levels, growth rates and respiratory abilities were adversely affected by air pollution, and that girls tend to be affected to a greater extent than boys. ${ }^{33}$

Lambda -cyhalothrin is an insecticide belonging to the pyrethroid family. ${ }^{34,35}$ Some studies report a burning sensation in the face and irritation in the upper respiratory tract after exposure to cyhalothrin. ${ }^{36,37}$ A study conducted in Tanzania showed that pesticide spray application can lead to irritation in the nose and throat as well 
as a burning sensation in the face and periorbital area within a few hours after application, and the duration of these complaints could last for a day. ${ }^{38}$ Our study revealed that cough, sputum production, wheezing, dyspnea, chest tightness as well as a burning sensation in the eyes, mouth, head, neck and throat could be observed in $59.7-88.8 \%$ of the children on the second day after cyhalothrin application outdoors (7 g/daa). While such complaints did not last for more than a day in the previously cited study ${ }^{38}$, the symptoms continued to exist $2 \mathrm{~d}$ after the pesticide application in our case. Most importantly, these symptoms were also accompanied by a decrease in mean PEF values of the children. Moreover, the affected person in the previously cited study ${ }^{38}$ was exposed to cyhalothrin $\left(25 \mathrm{mg} / \mathrm{m}^{2}\right)$ an indoor environment, and was less affected than the children in our study although the latter took place outdoors and the dose of cyhalothrin dosage was lower $\left(7 \mathrm{mg} / \mathrm{m}^{2}\right)$. This difference can be explained by the fact that children are more severely affected by pesticide application than adults. The possible explanations for this result include higher respiratory rates and shorter airways in children compared to adults.

A previous study in Ethiopia also showed significantly lower $\mathrm{FEV}_{1}$ and FVC values due to pesticide application in a group of young subjects aged 15-24 years. ${ }^{39}$ In our study, the PEF values of the children showed significant negative correlations with $\mathrm{PM}_{10}$ levels.

A previous work exploring the effects of organophosphate application in 279 children over 7 years in California, US, reported a significant decrease in the $\mathrm{FEV}_{1}$ and FVC values as a result of exposure at an early age to pesticides (dialkyl phosphate levels were measured in the urine). ${ }^{4}$ The American study also showed a long-term decline in respiratory function. Similarly, the significant accelerated decrease in the PEF values shortly after pesticide application in our study revealed that pesticides cause acute and adverse respiratory health outcomes in children.
Although our study was initiated with 266 children as participants, it eventually continued with only 72 children. Given the discomfort caused by the intensive pesticide application in this region, the farmers chose to shift temporarily to other regions during the pesticide application season. The data obtained from the 266 children before pesticide exposure and the pre-exposure data of the remaining 72 children were compared. The statistical comparisons provided similar results. Thus, one of the most important limitations of our study was that only one-third of the population before pesticide application continued participation after the application. The absence of a control group was another important limitation. Moreover, the pesticide ratios in the PM could not be measured.

In this study, the colour of the bare soil of the fields before pesticide application in June was red. After the cotton plants grew by July or August, the fields turned green and lush with the crop. The concentrations of airborne PM were expected to decrease with the increased amounts of moisture provided by irrigation, the decreased wind speed and the greening of the environment. However, the pesticide application increased PM levels.

The potential routes of pesticide exposure in children residing near these areas included contact with pesticide-contaminated clothing of the adults who applied the pesticides, air inhalation, contact with soil, crops and pesticide application devices as well as water consumption., ${ }^{2,40}$ The acutely impaired respiratory functions of the children in our study may be prevented by various approaches. The first approach involves temporarily shifting people from the agricultural area during periods of pesticide application to prevent exposure via air inhalation. Nonetheless, exposure to pesticide residues in the soil and environment is unavoidable. The second and most radical approach involves replacing pesticides with alternative substances. The use of pesticides should be controlled, and non-toxic pesticides should be encouraged. New harmless methods for protection against 
pests should be investigated. Another option involves cultivating pest-resistant plants. Further, to minimise human and environmental exposure arising from airborne pesticide residues, the potential for losses to the air should be considered when selecting pesticide formulations and application methods.

In addition to these measures, an early warning system can be established to detect respiratory disorders by tracking annual $\mathrm{PM}_{10}$ data in the region. ${ }^{41}$ Such a system can ensure the use of the best scientific tools to inform all those concerned about possible health exposures in a timely manner. Such a warning system can help in the planning of temporary relocation of the affected inhabitants of the region.

\section{Acknowledgements}

The authors wish to express their thanks to the Turkish Thoracic Society for providing financial support for this work.

\section{REFERENCES}

1. American Academy of Pediatrics .Roberts JR, Karr CJ; Council on Environmental Health. Pesticide exposure in children. Pediatrics 2012; 130: e1765-e1788.

2. Lu C, Fenske RA, Simcox NJ, Kalman D, Pesticide exposure of children in an agricultural community: evidence of household proximity to farmland and take home exposure pathways. Environ Res 2000; 84: 290-302.

3. Harnly ME, Bradman A, Nishioka M, et al. Pesticides in dust from homes in an agricultural area. Environ Sci Technol 2009; 43: 8767-8774.

4. Raanan R, Balmes JR, Harley KG, et al. Decreased lung function in 7-year-old children with early-life organophosphate exposure. Thorax 2016; 71: 148153.

5. Haryanto B. Air Pollution A Comprehensive Perspective. Croatia: InTech, 2012. Available at: https://www.intechopen.com/books/air-pollution-acomprehensive-perspective (Accessed on April 16, 2021).

6. Lopez A, Yusa V, Muñoz A, et al. Risk assessment of airborne pesticides in a Mediterranean region of Spain. Sci Total Environ 2017; 574: 724-734.
7. Nascimento MM, da Rocha GO, de Andrade JB. Pesticides in fine airborne particles: from a green analysis method to atmospheric characterization and risk assessment. Sci Rep 2017; 7: 2267.

8. Varga, G, Újvári G, Kovács, J.Spatiotemporal patterns of Saharan dust outbreaks in the Mediterranean Basin. Aeolian Res 2014; 15: 151-160.

9. Rastgeldi Dogan T, Saydam AC, Yesilnacar MI, Gencer M. In-cloud alteration of desert-dust matrix and its possible impact on health: a test in southeastern Anatolia, Turkey. Eur J Mineral 2010; 22: 659-664.

10. MacLean JE, Fitzgerald DA, Waters KA. Developmental changes in sleep and breathing across infancy and childhood. Paediatr Respir Rev 2015; 16: 276-284.

11. Bateson TF, Schwartz J. Children's response to air pollutants. J Toxicol Environ Health Part A 2008; 71: 238-243.

12. UNICEF. Clear the air for children. UNICEF Publications, 2016. Available at: https://www.unicef. org/reports/clean-air-children. (Accessed on April 16, 2021.)

13. Bayer-Oglesby L, Grize L, Gassner M, et al. Decline of ambient air pollution levels and improved respiratory health in Swiss children. Environ Health Perspect 2005; 113: 1632-1637.

14. Mehta B, Garg K, Ambwani S, Bhandari B, Bhagat OL. Peak expiratory flow rate: a useful tool for early detection of airway obstruction in school children. Open Med J 2016; 3: 159-165.

15. Pedersen OF, Miller MR, Sigsgaard T, Tidley M, Harding RM. Portable peak flow meters: physical characteristics, influence of temperature, altitude, and humidity. Eur Respir J1994; 7: 991-997.

16. Hong YC, Pan XC, Kim SY, et al. Asian dust storm and pulmonary function of school children in Seoul. Sci Total Environ 2010; 408: 754-759.

17. Pesticide Market Estimates: 2006-2007. Available at: http://www.epa.gov (Accessed on November 15, 2019).

18. Food and Agriculture Organization of the United Nations (FAO). Database on Pesticides Consumption. Available at: http://www.fao.org (Accessed on November 15, 2019).

19. Vrijheid M, Casas M, Gascon M, Valvi D, Nieuwenhuijsen M. Environmental pollutants and child health-A review of recent concerns. Int J Hyg Environ Health 2016; 219: 331-342.

20. Steenland K, Mora AM, Barr DB, Juncos J, Roman $\mathrm{N}$, Wesseling C. Organochlorine chemicals and neurodegeneration among elderly subjects in Costa Rica. Environ Res 2014; 134: 205-209. 
21. Sagiv SK, Thurston SW, Bellinger DC, Tolbert PE, Altshul LM, Korrick SA. Prenatal organochlorine exposure and behaviours associated with attention deficit hyperactivity disorder in school-aged children. Am J Epidemiol 2010; 171: 593-601.

22. Saunders L, Kadhel P, Costet N, et al. Hypertensive disorders of pregnancy and gestational diabetes mellitus among French Caribbean women chronically exposed to chlordecone. Environ Int 2014; 68: 171-176.

23. Freire C, Koifman RJ, Sarcinelli PN, Rosa ACS, Clapauch R, Koifman S. Association between serum levels of organochlorine pesticides and sex hormones in adults living in a heavily contaminated area in Brazil. Int J Hyg Environ Health 2014; 217: 370-78.

24. O'Malley M. Clinical evaluation of pesticide exposure and poisonings. Lancet 1997; 349: 11611166.

25. Sanborn MD, Cole D, Abelsohn A, Weir E. Identifying and managing adverse environmental health effects: 4 Pesticides. Can Med Assoc J 2002; 166: 1431-1436.

26. Alif SM, Dharmage SC, Benke G, et al. Occupational exposure to pesticides are associated with fixed airflow obstruction in middle-age. Thorax 2017; 72: 990-997.

27. Raanan R, Harley KG, Balmes JR, Bradman A, Lipsett M, Eskenazi B, Early-life exposure to organophosphate pesticides and pediatric respiratory symptoms in the CHAMACOS cohort. Environ Health Perspect 2015; 123: 179-185.

28. Ndlovu V, Dalvie MA, Jeebhay MF. Asthma associated with pesticide exposure among women in rural Western Cape of South Africa. Am J Ind Med 2014; 57: 1331-1343.

29. Hoppin JA, Umbach DM, London SJ, et al. Pesticide use and adult-onset asthma among male farmers in the Agricultural Health Study. Eur Respir J 2009; 34: 1296-1303.

30. Hoppin JA, Valcin M, Henneberger PK, et al. Pesticide use and chronic bronchitis among farmers in the agricultural health study. Amer J Ind Med 2007; 50: 969-979.
31. Ceylan E. Şanlıurfa'da tahıl polen duyarlılığı ve astım kliniğine etkisi. Klinik ve Analitik Tıp Dergisi 2012; 3: 328-330.

32. Bıçakçı A, Çelenk S, Altunoglu MK, et al. Allergenic airborne Gramineae (Grass) pollen concentrations in Turkey. Türkiye'de allerjenik gramineae (çayır, çimen vb.) polenlerinin havadaki dağılımları. Asthma Allergy Immunol 2009; 7: 90-99.

33. Clougherty JE. A growing role for gender analysis in air pollution epidemiology. Environ Health Perspect 2010; 118: 167-176.

34. World Health Organization. Environmental Health Criteria 99 Cyhalothrin. Geneva, Switzerland, 1990. Available at: https:/wedocs.unep.org/bitstream/ handle/20.500.11822/29411/EHC99Cyhathn. pdf? sequence $=1 \&$ isAllowed=y (Accessed on April 16, 2021).

35. Lambda-cyhalothrin; pesticide tolerances. Fed Regist 1998; 63: 7291-7299.

36. He F, Wang S, Liu L, Chen S, Zhang Z, Sun J, Clinical manifestations and diagnosis of acute pyrethroid poisoning. Arch Toxicol 1989; 63: 54-58.

37. Pauluhn J, Steffens W, Haas J, et al. Toxicologic evaluation of pyrethroids in indoor air: demonstrated with the example of cyfluthrin and permethrin. Gesundheitswesen 1996; 58: 551-556.

38. Moretto A. Indoor spraying with the pyrethroid insecticide lambda-cyhalothrin: effects on spraymen and inhabitants of sprayed houses. Bull World Health Organ 1991; 69: 591-94.

39. Mekonnen Y, Agonafir T. Lung function and respiratory symptoms of pesticide sprayers in state farms of Ethiopia. Ethiop Med J 2004; 42: 261-266.

40. Curl CL, Fenske RA, Kissel JC, et al. Evaluation of take-home organophosphorus pesticide exposure among agricultural workers and their children. Environ Health Perspect 2002; 110: A787-A792.

41. Mo X, Zhang L, Li H, Qu Z. A novel air quality earlywarning system based on artificial intelligence. Int J Environ Res Public Health 2019; 16: 3505. 